\title{
Internet Addiction among Undergraduate Students of a Medical College in North India
}

\author{
Seema Jain ${ }^{1}$, Vertika Agarwal ${ }^{2}$, Sunil Kumar Garg ${ }^{3}$
}

\begin{abstract}
Abstarct
Aim and objective: To assess the pattern of Internet use, to classify levels of Internet addiction, and to find out possible associated factors related to Internet addiction

Materials and methods: This cross-sectional study was conducted in 2018 on undergraduate students of a medical college. The participants were asked to fill a questionnaire that had two parts. Part 1 was a semi-structured self-administered questionnaire pertaining to sociodemographic profile and characteristics of the Internet and computer use, and part 2 contained Internet addiction scale to evaluate internet addiction level of these students. The data collected were analyzed using appropriate statistical methods.

Results: In all, $70.6 \%$ of undergraduate medical students had some degree of Internet addiction. The factors statistically associated with Internet addiction were gender, place of living, login status, purpose of Internet use, average Internet use per day, and expenditure on Internet usage. Conclusion: According to this study, the prevalence of internet addiction was high among medical students. We recommend controlling Internet addiction by building healthy living environment around these students, promoting other activities like book reading and sports, and providing counseling to those with addiction.

Clinical significance: Internet addiction is a budding health problem and more so in college students.

Keywords: Cross-sectional study, Internet addiction, Medical students, North India, Young's internet addiction scale.

Journal of Medical Academics (2020): 10.5005/jp-journals-10070-0049
\end{abstract}

\section{INTRODUCTION}

The advent of computers and the Internet has led to significant changes and development in the way knowledge and information is generated and stored. Today, Internet has become an indispensable tool not only as means of communication and entertainment but also in academics, business, banking, shopping, online search, etc. The use of Internet has escalated to such proportions that other important works are often neglected, and people have become dependent on Internet in everyday life. The Internet and mobile association of India reports that in the year 2017 approximate number of active Internet users in India were 456 million which was further estimated to increase to 478 million by $2018 .{ }^{1}$

In year 1995, Dr Ivan Goldberg proposed the term "Internet addiction" for pathological compulsive use of Internet. With development of online learning, communication, and entertainment, the Internet has become an essential tool for the youth, especially students. ${ }^{2}$ With rapid advancement in health science, use of Internet has substantially increased over past few years among medical students to keep pace with latest knowledge and also because of ease of availability of medical content online.

Studies have shown that Internet addiction is a worldwide phenomenon with a prevalence varying greatly from 0.3 to $38 \%$ depending upon the population studied, methodology of study, and diagnostic instrument used. Researches have also revealed that the most affected population is youth, especially college students. ${ }^{3}$ A meta-analysis on prevalence of Internet addiction in medical students found a pooled prevalence of $30.1 \%$ which is 5 times more than that of the general population. ${ }^{4}$

It is seen that an uncontrolled and improper use of Internet has a negative psychosocial impact on the youth which if not controlled can pose as an important health-related problem in the near future. Understanding the gravity of problem and lack of substantial data
${ }^{1-3}$ Department of Community Medicine, Lala Lajpat Rai Memorial Medical College, Meerut, Uttar Pradesh, India

Corresponding Author: Vertika Agarwal, Department of Community Medicine, Lala Lajpat Rai Memorial Medical College, Meerut, Uttar Pradesh, India, Phone: +91 9759833590, e-mail: drvertika.0620@gmail. com

How to cite this article: Jain S, Agarwal V, Garg SK. Internet Addiction among Undergraduate Students of a Medical College in North India. J Med Acad 2020;3(1):14-16.

Source of support: Nil

Conflict of interest: None

in this regard, especially in Northern India, we planned this study with an aim to assess the pattern of Internet use, to classify levels of Internet addiction according to Young's IAT, and to find out factors, if any, associated with Internet addiction among undergraduate medical students studying in LLRM Medical College, Meerut.

\section{Materials and Methods}

This cross-sectional study was conducted from November 2018 to January 2019. Among 600 undergraduate medical students of first, second, third, and fourth (part 1) professional studying in LLRM Medical College, all the students present on the day of data collection and consented to participate were included in the study. Students were asked to fill a self-administered questionnaire that had two parts. Part 1 had semi-structured questions pertaining to respondents Internet usage and general profile. Part 2 was an Internet addiction scale-The Young's internet addiction scalewhich is a 20 -item scale that measures the presence and severity of Internet dependency. Each class was contacted twice at interval 
of 3 days. Students who were absent even after 3 days of contact or gave incomplete questionnaire were excluded. Data thus collected were analyzed using on Epi info 7.0. Chi-square test was applied for statistical analysis, and $p$ value $<0.05$ was considered statistically significant.

\section{Young's Internet Addiction Test Scale (Young's IAT Scale)}

This scale was devised by Dr Kimberly Young, a professor at St. Bonaventure University and director of the Center for Internet Addiction Recovery, to assess symptoms of Internet addiction and compulsivity in a variety of test settings. The IAT scale measures the severity of self-reported compulsive use of the Internet in adults and adolescents. It is the most widely used validated Internet addiction scale. ${ }^{5,6}$

The 20-item questionnaire measures characteristics and behaviors associated with compulsive use of the Internet that includes compulsivity, escapism, and dependency. Questions also assess problems related to addictive use in personal, occupational, and social functioning. Questions are randomized, and each statement is weighted along a Likert-scale continuum that ranges from 0 (less extreme behavior) to 5 (most extreme behavior) for each item. The IAT total score is the sum of the ratings given by the examinee for the 20 -item responses with a maximum score of 100 points. The higher score represents higher level of severity of Internet compulsivity and addiction. Total scores that range from 0 to 30 points are considered to reflect a normal level of Internet usage; scores of 31 to 49 indicate the presence of a mild level of Internet addiction; 50 to 79 reflect the presence of a moderate level; and scores of 80 to 100 indicate a severe dependence upon the Internet. The Young's IAT scale is validated in various languages including English which was used in this study. ${ }^{6}$

\section{Results}

A total of 466 students studying in different levels of undergraduate were included in the study. As 90 students were absent on the day of data collection and 44 submitted incomplete questionnaires, they were excluded. The mean age of participants was $21 \pm 1.7$ years. It was found that $55.2 \%$ of students were male and $44.8 \%$ were females. Among all, 90.3\% students were hosteller/paying guest, and only $9.7 \%$ were living at home. For accessing Internet, $97.0 \%$ students used smartphones, while only 3\% used laptop/desktop. Most common mode of access was by mobile Internet (95.8\%), followed by broadband/data card (3\%), and wifi (1.2\%).

As observed in Figure 1, only $29.4 \%$ were under category of normal usage, while $70.6 \%$ of students had some degree of Internet addiction with $38.4 \%$ having mild addiction, $29.6 \%$ moderate, and $2.6 \%$ severe addiction. Table 1 show the mean scores of IAT scale in different categories of severity.

It was also found that in only $17.6 \%$ students the main purpose of using Internet was for academic reasons, while in $82.4 \%$ students it was primarily for nonacademic activities, which include social networking (39.4\%), followed by downloadable media including movies/videos(25.0\%), pornography (12.7\%), online shopping (12.0\%), and others including online gaming, gambling, etc (10.9\%).

As shown in Table 2, the factors statistically associated with Internet addiction were gender, place of living, login status, purpose of Internet use, average Internet use per day, and expenditure on Internet usage. However, years of Internet usage was not found statistically significant.

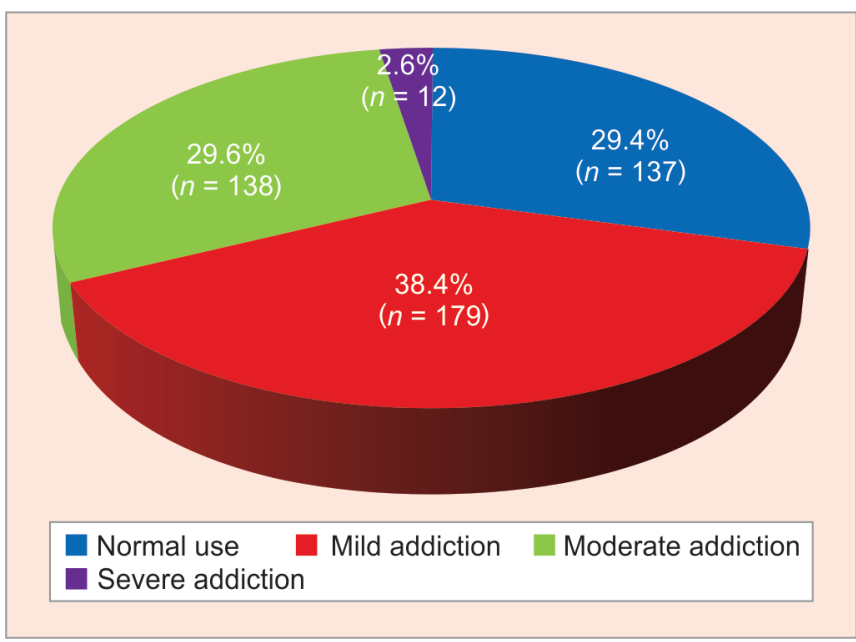

Fig. 1: Prevalence of internet addiction

Table 1: Mean scores of Young's internet addiction test scale among medical students

\begin{tabular}{lllll}
\hline & $\begin{array}{l}\text { Normal } \\
\text { usage }\end{array}$ & $\begin{array}{l}\text { Mild } \\
\text { addiction }\end{array}$ & $\begin{array}{l}\text { Moderate } \\
\text { addiction }\end{array}$ & $\begin{array}{l}\text { Severe } \\
\text { addiction }\end{array}$ \\
\hline $\begin{array}{l}\text { Mean } \\
\text { scores }\end{array}$ & $21.16 \pm 6.5$ & $39.72 \pm 5.4$ & $60.21 \pm 8.3$ & $87.25 \pm 4.09$ \\
\hline
\end{tabular}

\section{Discussion}

The present study investigated the problem of Internet addiction among undergraduate medical students. It was observed that $70.6 \%$ students had varying degree of Internet addiction which is much lower to the prevalence of reported by Ade et al. ${ }^{7}$ (89.0\%) in medical students in Pune. However, some studies have also shown lower prevalence like Duraimurugan et al. ${ }^{8}$ with $56.6 \%$ and Chaudhari et al. ${ }^{3}$ with $58.7 \%$. In the present study, 38.4\% were mild addict, $29.6 \%$ moderate, and $2.58 \%$ severe addicts which is much lower to findings of Ade et al. ${ }^{7}$ being $64.0 \%, 22.0 \%$, and $6.0 \%$, respectively.

Gender difference was observed in prevalence of Internet addiction, with $74.7 \%$ male students and $65.5 \%$ female students suffering Internet addiction to varying degree. This is contrary to findings of Ade et al. ${ }^{7}$ who did not notice any gender disparity in their study. ${ }^{7}$

It was also observed that addicts spent greater amount of time and money on internet usage when compared to non-addicts, which could lead to distractions from academic achievements and can cause financial problems. It was also observed that the most common content accessed was non-academic. Similar findings were reported by Ade et al. ${ }^{7}$ Such behavior deviates student from attaining academic excellence.

\section{Conclusion}

We found a high prevalence of Internet addiction (70.6\%) among medical students with $2.58 \%$ severe, $29.6 \%$ moderate, and $38.4 \%$ mild addiction, which is a dark reality requiring timely remedial actions. We recommend implementation of appropriate interventions and restrictions to encourage rational use of Internet. Comprehensive program can be prepared to increase awareness among students about Internet addiction and its negative impact on health along with provision of healthy living environment with 
Internet Addiction among Undergraduate Students of a Medical College in North India

Table 2: Association of internet addiction with various factors

\begin{tabular}{|c|c|c|c|c|c|c|}
\hline Variables & $\begin{array}{l}\text { Normal user } \\
(n=137)\end{array}$ & $\begin{array}{l}\text { Mild addiction } \\
(n=179)\end{array}$ & $\begin{array}{l}\text { Moderate addiction } \\
(n=138)\end{array}$ & $\begin{array}{l}\text { Severe addiction } \\
(n=12)\end{array}$ & Total & $\begin{array}{l}\text { Chi-square value, } p \\
\text { value }\end{array}$ \\
\hline \multicolumn{7}{|l|}{ Gender } \\
\hline Male & $65(25.3)$ & $100(38.9)$ & $82(31.9)$ & $10(3.9)$ & $257(100)$ & \multirow[t]{2}{*}{$\chi^{2}=8.196, p=0.042$} \\
\hline Female & $72(34.5)$ & $79(37.8)$ & $56(26.8)$ & $02(0.9)$ & $209(100)$ & \\
\hline \multicolumn{7}{|l|}{ Living place } \\
\hline Hostel/PG & $116(27.5)$ & $164(38.9)$ & $129(30.6)$ & $12(2.8)$ & $421(100)$ & \multirow[t]{2}{*}{$\chi^{2}=8.226, p=0.042$} \\
\hline Home & $21(46.7)$ & $15(33.3)$ & $9(20)$ & $0(0)$ & $45(100)$ & \\
\hline \multicolumn{7}{|l|}{ Login status } \\
\hline Always online & $37(18.6)$ & $66(33.2)$ & $85(42.7)$ & $11(5.5)$ & $199(100)$ & \multirow[t]{2}{*}{$\chi^{2}=48.16, p<0.001$} \\
\hline Occasionally & $100(37.4)$ & $113(42.3)$ & $53(19.9)$ & $1(0.4)$ & $267(100)$ & \\
\hline \multicolumn{7}{|c|}{ Purpose of internet use } \\
\hline Academic & $32(39.4)$ & $34(41.4)$ & $12(14.6)$ & $4(4.9)$ & $82(100)$ & \multirow[t]{2}{*}{$\chi^{2}=12.97, p=0.005$} \\
\hline Non-academic & $105(27.3)$ & $145(37.8)$ & $126(32.8)$ & $8(2.1)$ & $384(100)$ & \\
\hline \multicolumn{7}{|c|}{ Years of internet usage } \\
\hline$\leq 3$ years & $43(37.7)$ & $40(35.1)$ & $29(25.4)$ & $2(1.8)$ & $114(100)$ & \multirow[t]{4}{*}{$\chi^{2}=9.28, p=0.412$} \\
\hline $4-6$ years & $55(27.9)$ & $76(38.6)$ & $61(31.0)$ & $5(2.5)$ & $197(100)$ & \\
\hline $7-10$ years & $24(25.3)$ & $42(44.2)$ & $25(26.3)$ & $4(4.2)$ & $95(100)$ & \\
\hline$>10$ years & $15(25)$ & $21(35.0)$ & $23(38.3)$ & $1(1.7)$ & $60(100)$ & \\
\hline \multicolumn{7}{|c|}{ Average internet use per day } \\
\hline$<4$ hours & $113(39.1)$ & $115(39.7)$ & $59(20.4)$ & $2(0.7)$ & $289(100)$ & \multirow[t]{3}{*}{$\chi^{2}=48.16, p<0.001$} \\
\hline $4-7$ hours & $20(11.7)$ & $86(50.3)$ & $58(33.9)$ & $7(4.1)$ & $171(100)$ & \\
\hline$>7$ hours & $4(5)$ & $52(65)$ & $21(26.3)$ & $3(3.7)$ & $80(100)$ & \\
\hline \multicolumn{7}{|c|}{ Expenditure on internet per month (in INR) } \\
\hline Rs. $<400$ & $95(30.8)$ & $123(39.9)$ & $87(28.2)$ & $3(1)$ & $308(100)$ & \multirow[t]{3}{*}{$\chi^{2}=23.35, p=0.001$} \\
\hline Rs. $400-800$ & $33(32.3)$ & $36(35.3)$ & $30(29.4)$ & $3(2.9)$ & $102(100)$ & \\
\hline Rs. $>800$ & $9(16.1)$ & $20(35.7)$ & $21(37.5)$ & $6(10.7)$ & $56(100)$ & \\
\hline
\end{tabular}

promotion of activities, such as book reading, sports, and other hobbies that can aid in minimizing smart phone use. Faculty must be trained to detect students at risk of addiction before it becomes pathological. Those suffering with addiction can be offered counseling and cognitive behavior therapy for Internet addiction (CBT-IA).

\section{Ethical Clearence}

Institute's Ethical Committee.

\section{References}

1. IAMAI and Kantar IMRB-Mobile Internet Report-2017. available on https://cms.iamai.in/Content/ResearchPapers/2b08cce4-e571-4cfe9f8b-86435a12ed17.pdf (Last accessed on 20 May, 2020.).

2. Goel D, Subramanyam A, Kamath R. A study on the prevalence of internet addiction and its association with psychopathology in Indian adolescents. Indian J Psychiat 2013;55(2):140-143. DOI: 10.4103/00195545.111451.
3. Chaudhari B, Menon P, Saldanha D, et al. Internet addiction and its determinants among medical students. Ind Psychiatry J 2015;24(2):158-162. DOI: 10.4103/0972-6748. 181729.

4. Zang MWB, Lim RB, Lee $C$, et al. Prevalence of internet addiction in medical students: a meta-analysis. Acad Psychiatry 2018;42(1):88-93. DOI: 10.1007/s40596-017-0794-1.

5. Laconi S, Rodgers RF, Chabrol H. The measurement of internet addiction: a critical review of existing scales and their psychometric properties. Comput Human Behav 2014;41:190-202. DOI: 10.1016/j. chb.2014.09.026.

6. Internet addiction test user manual. accessed through http:// cyberpsy.ru/wp-content/uploads/2018/02/iat-manual.pdf on 21.102018.

7. Ade $D$, Khare A, Kayande S. Study of internet addiction in undergraduate medical students. IOSR J Dent Med Sci 2018;17(3): 51-55.

8. Paul AVR, Ganapathi CK, Duraimurugan M, et al. Internet addiction and associated factors: a study among college students in South India. IJMHS 2015;5(3):121-125. 